\title{
Histamine release during paediatric cardiopulmonary bypass
}

Davinia E. Withington FRCA MRCP, ${ }^{1 *}$ Wing K. Man $\mathrm{PhD}^{2}{ }^{2}$ Martin J. Elliott MD FRCs. ${ }^{3}$
Histamine release is part of the general inflammatory response and occurs during surgery and cardiopulmonary bypass (CPB) in adults. Few data are available for children. Histamine release was studied in 23 children undergoing CPB with standard anaesthetic and CPB techniques. Blood sampling was performed in relation to specific anaesthetic and surgical events, e.g., start of $C P B$, removal of aortic clamps, reventilation of the lungs. Plasma histamine was determined by a single isotope radioenzymatic technique. There was no consistent histamine release in the study population although there was an increase in plasma histamine concentration in some subjects after initiation of $C P B(P<0.05)$ and on removal of the aortic cross-clamp $(P<0.05)$. No correlation was demonstrated between histamine concentration and systolic arterial pressure, temperature, duration of CPB or cross-clamp time. Histamine concentration was positively correlated with heart rate.

La libération d'histamine participe à la réaction inflammatoire systémique et survient pendant la chirurgie et la circulation extra-corporelle chez l'adulte (CEC). On ne dispose que peu de données pédiatriques. La libération histaminique est étudiée

\section{Key words}

ANAESTHESIA: paediatric;

HISTAMINE:

SURGERY: cardiopulmonary bypass.

From the Departments of Anaesthesia, St. Thomas' Hospital, Lambeth Palace Road, London SE1 7EH ${ }^{1}$, Surgery, Royal Postgraduate Medical School, Du Cane Road, London ${ }^{2}$ W12 OHS and Cardiothoracic Surgery, Hospital for Sick Children, Great Ormond Street, London, WCIN 3JH ${ }^{3}$, U.K.

Address correspondence to: Dr. D.E. Withington, *Current address: Department of Anaesthesia, Montreal Children's Hospital, Rue Tupper, Montreal, H3H 1P3, Canada.

Presented in part at 1991 annual meetings of the International Anesthesia Research Society and the European Histamine Research Society.

Accepted for publication 1Ith December, 1992. chez 23 enfants qui subissent une CEC avec une technique anesthésique standard. Des échantillons de sang sont prélevés au moment d'événements anesthésiques et chirurgicaux prédéterminés, e.g., début de la CEC, déclampage aortique, réinsufflation des poumons. Lhistamine plasmatique est déterminée par la seule technique isotopique radioenzymatique. La libération d'histamine ne survient pas de façon régulière dans la population étudiée bien que chez quelques sujets on trouve une augmentation de sa concentration plasmatique après la mise en marche de la CEC $(P<0,05)$ et au déclampage de l'aorte $(P<0,05)$. Il n'y a aucune corrélation entre la concentration d'histamine d'une part, et la pression artérielle systolique, la température, la durée de la CEC ou la durée du clampage d'autre part. Il existe toutefois une corrélation positive avec la fréquence cardiaque.

Elevated plasma histamine concentrations have been reported during several general surgical procedures including thoracotomy, aorto-bifemoral bypass and cholecystectomy. ${ }^{1}$ Histamine release has also been demonstrated during cardiopulmonary bypass (CPB) in adults ${ }^{2}$ and in children. ${ }^{3}$ This phenomenon is of concern during CPB because of the potent cardiac and vaso-active effects of histamine. These include increased capillary permeability, positive inotropism and chronotropism, ${ }^{4-6}$ induction of dysrhythmias ${ }^{7}$ and constriction of coronary and pulmonary circulations. 8,9

Histamine has been implicated in the causation of postCPB capillary leak syndrome which results in tissue oedema and organ dysfunction. Smaller children and those with longer bypass times have worse capillary leak. ${ }^{10}$

Pulmonary vasoconstriction is of particular concern in the paediatric population as many children with congenital heart disease have high pulmonary vascular resistance (PVR) and oxygenation is critically dependent on the balance between systemic and pulmonary circuits. Any factor which may affect this balance merits further investigation. Therefore, following a pilot study, ${ }^{11}$ we have undertaken a descriptive study to elucidate the relationship between histamine release and surgical events during paediatric cardiac surgery. 


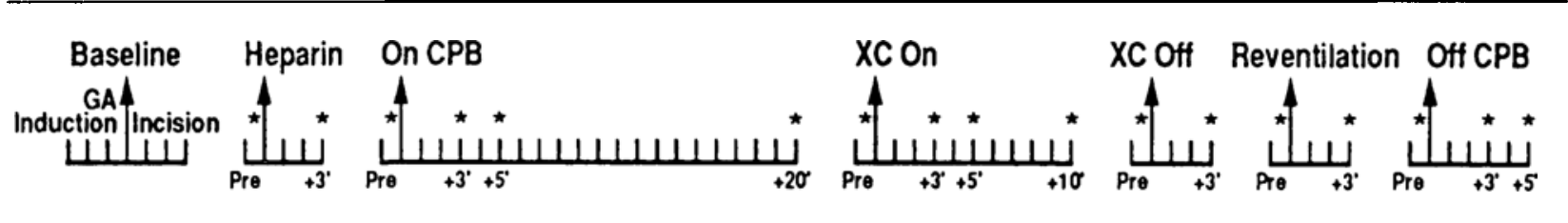

FIGURE I Schedule for plasma histamine sampling. Timing of sampling in minutes after events denoted by asterisks. $\mathrm{CPB}=$ cardiopulmonary bypass; $\mathrm{XC}=$ aortic cross-clamp.

\section{Methods}

With Hospital Ethics Committee approval 23 children undergoing CPB for the correction of a variety of congenital heart anomalies were studied. Patients taking drugs known to affect histamine release were prospectively excluded. The study was performed in the context of our standard practice, thus there was no change from normal anaesthetic or surgical protocols.

All children received a standard opiate/anticholinergic premedication. ${ }^{12}$ Anaesthesia was induced with cyclopropane in oxygen or with intravenous thiopentone, ${ }^{13}$ and muscle relaxation was achieved and maintained with succinylcholine (1-2 $\left.\mathrm{mg} \cdot \mathrm{kg}^{-1}\right)$ and pancuronium (0.1 $\mathrm{mg} \cdot \mathrm{kg}^{-1}$ ). Anaesthesia was maintained with $\mathrm{N}_{2} \mathrm{O}$, isoflurane and fentanyl as appropriate. In 18 patients the extracorporeal circuit was primed with stored blood and Hartmann's solution, and in five with a clear prime of Plasmalyte 148 (Travenol) or Hartmann's solution. Sodium bicarbonate and mannitol were added to both types of prime. Hollow fibre membrane oxygenators were used in all cases and cardioplegia (St. Thomas' Hospital I solution) was administered after cross-clamping the aorta. Patients were core-cooled as appropriate on the pump. Rewarming after cross-clamp removal was achieved by the CPB heater and the use of a sodium nitroprusside (SNP) infusion $\left(0.5 \mu \mathrm{g} \cdot \mathrm{kg}^{-1} \cdot \mathrm{min}^{-1}\right)$ to improve peripheral perfusion.

Blood samples were taken according to the regimen shown in Figure 1. No samples were taken before induction of anaesthesia as the majority of children were anaesthetised with cyclopropane. Baseline samples were taken as along after induction as possible but before skin incision to enable histamine release produced by premedicant or anaesthetic drugs to subside. Baseline and pre-bypass levels were taken to isolate the effects of induction drugs and heparin. Thereafter, the effect of specific events was examined by comparing histamine concentrations before and after specific events. Events of particular interest in the light of previous studies were initiation of CPB, removal of the aortic cross-clamp and reventilation of the lungs. Samples were not taken after protamine administration in 11 cases as no elevation of histamine concentration had been found after protamine in our first 12 subjects.
All pre-CPB samples were taken from the arterial line. A sample was taken from the pump prime before CPB commenced. Once on bypass, samples were taken from the pump reservoir until a left atrial (LA) line could be inserted. Samples were then taken in parallel from the right atrial (RA) line and LA line before lung inflation, three, and five minutes afterwards.

All samples were taken into EDTA tubes on ice and cold centrifuged at $2000 \mathrm{rpm}$ for ten minutes. The plasma was frozen at $-20^{\circ} \mathrm{C}$ until assayed. A single isotope radioenzymatic assay technique (sensitivity $0.05 \mathrm{ng} \cdot \mathrm{ml}^{-1}$ ) was used. ${ }^{14}$ Results were not corrected for haemodilution as our interest was in actual histamine concentrations rather than attempting to measure total histamine release.

Mean arterial pressure (MAP), heart rate (HR) and temperature were recorded at each sampling point. Thermodilution catheters were not routinely inserted therefore SVR and PVR could not be calculated.

The results were examined statistically by comparing histamine values before and after specific events by ANOVA and the paired $t$ test after checking for normal distribution. Correlations were performed with the Oxstat II version 1.1 statistics programme.

\section{Results}

Twenty-three patients were studied with an age range of 9 mo to 14.4 yr. Demographic data and details of each procedure are shown in Table I.

Plasma histamine concentrations may be compared with mean basal plasma histamine as determined in several large series of normal volunteers and patients $(0.3$ $\left.\mathrm{ng} \cdot \mathrm{ml}^{-1}\right) .{ }^{15}$ The histamine concentrations varied considerably between subjects (Figure 2). Four children had moderately elevated baseline levels (300-400\% normal), while another 12 had slight elevation. In all but one patient the histamine concentration was less that 0.7 $\mathrm{ng} \cdot \mathrm{ml}^{-1}$ before heparin was administered. One child had a baseline of $0.84 \mathrm{ng} \cdot \mathrm{ml}^{-1}$ increasing to $9.13 \mathrm{ng} \cdot \mathrm{ml}^{-1}$ before heparin. The concentration gradually decreased to normal during the first ten minutes of CPB and did not rise again during bypass.

Neither heparin nor protamine administration (studied in 12 cases) caused an increase in histamine. All prime samples had histamine concentrations of $<1.5 \mathrm{ng} \cdot \mathrm{ml}^{-1}$. 
TABLE I Demographic data

\begin{tabular}{ccllll}
\hline Patient & Age $(\mathrm{mo})$ & Operation & Prime & Cross-clamp time (min) & CPB time (min) \\
\hline 1 & 9 & ASD repair & Blood & 7 & 20 \\
2 & 10 & AVSD repair & Blood & 99 & 140 \\
3 & 11 & Switch & Clear & 122 & 243 \\
4 & 11 & Switch procedure & Clear & 122 & 243 \\
5 & 18 & VSD repair & Blood & 60 & 180 \\
6 & 22 & TOF correction & Blood & 50 & 107 \\
7 & 24 & VSD repair; PA deband & Blood & 77 & 115 \\
8 & 26 & VSD repair; PA deband & Clear & 107 & 154 \\
9 & 45 & AVSD repair & Blood & 116 & 152 \\
10 & 50 & TOF correction & Blood & 77 & 125 \\
11 & 52 & TOF correction & Clear & 61 & 132 \\
12 & 52 & ASD repair & Blood & 12 & 35 \\
13 & 55 & Homograft to PA & Blood & - & 106 \\
14 & 65 & AVSD repair & Blood & 39 & 60 \\
15 & 66 & TOF correction & Blood & 45 & 94 \\
16 & 84 & VSD repair; RV-PA conduit & Blood & 20 & 114 \\
17 & 86 & Sub-aortic stenosis repair & Blood & 27 & 60 \\
18 & 92 & VSD + AV repairs & Blood & 80 & 123 \\
19 & 98 & Fontan & Blood & 50 & 116 \\
20 & 102 & TOF correction & Blood & 35 & 108 \\
21 & 103 & PA repair & Clear & 92 & 136 \\
22 & 132 & Rastelli & Blood & 106 & 219 \\
23 & 172 & Redo fallot repair homograft & Blood & 80 & 213 \\
\hline
\end{tabular}

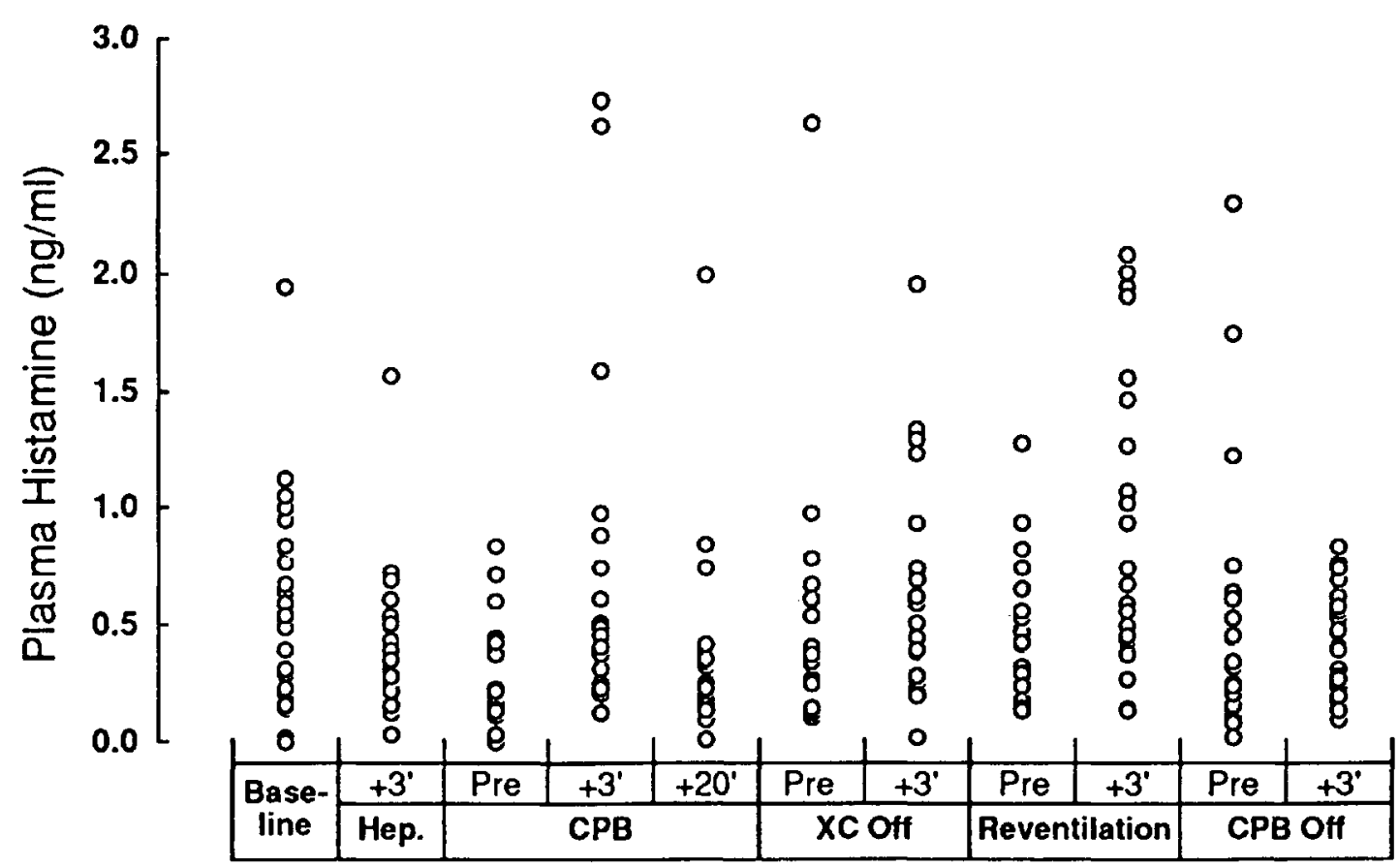

FIGURE 2 Scattergram of plasma histamine concentrations. Hep = heparin; $\mathrm{CPB}=$ cardiopulmonary bypass; $\mathrm{XC}=$ aortic cross clamp removal. Times are minutes after each event. Sample results before heparin, at $\mathrm{CPB}+5^{\prime}$, and after $\mathrm{XC}$ application, $5^{\prime}$ after reventilation and $5^{\prime}$ after end of CPB are omitted for clarity. 
TABLE II Statistical analysis of histamine release at start of CPB and at aortic cross-clamp removal

\begin{tabular}{lllll}
\hline & Pre-CPB & Post-CPB & Pre XC off & Post XC off \\
\hline Mean & 0.31 & 0.69 & 0.48 & 0.74 \\
Range & $0.03-0.84$ & $0.15-2.73$ & $0.02-2.64$ & $0.13-1.96$ \\
SD & 0.22 & 0.68 & 0.55 & 0.45 \\
Mean dif & 0.386 & & 0.257 & \\
Median dif & 0.140 & & 0.255 & 0.03 \\
$P$ & & 0.026 & & 0.03 \\
\hline
\end{tabular}

Plasma histamine concentrations are in $\mathrm{ng} \cdot \mathrm{ml}^{-1}$.

On starting CPB 14 children showed an increase in histamine which was $>300 \%$ in five; seven showed a decrease and two no change. On cross-clamp application 13 showed a small rise, five a decrease and four no change (in one child the aorta was not cross-clamped). These concentrations were very similar to those at CPB + 20 min and are not shown in Figure 2. On cross-clamp removal 13 showed an increase, $>300 \%$ in three; there was no change in two and no decreases. Data were missing for this period in seven cases. Reventilation of the lungs was followed by an increase in histamine concentration in 13 cases, $>300 \%$ in four, a decrease in nine and no change in two. On cessation of CPB eight children had a slight increase in histamine concentration, ten had a decrease and five were unchanged.

Using ANOVA and paired t testing the histamine concentrations changed significantly on only two occasions: on initiation of CPB and at aortic cross-clamp removal. However, the actual histamine concentrations at these times were relatively low (Table II). There was no difference between right and left atrial histamine concentrations either before or after reventilation of the lungs.

Regression analysis found no correlation between histamine concentration and MAP, temperature or rate of change of temperature. However, there was a positive correlation with $\mathrm{HR}(P<0.01)$.

The sub-groups receiving thiopentone or cyclopropane for induction were compared. There was no difference in baseline histamine concentration between the two nor did the method of induction influence the degree of elevation of plasma histamine at the start of bypass.

Histamine release was not related to age and neither CPB time nor cross-clamp time correlated with histamine concentration at the end of these respective periods. There was no evidence of continuing histamine release during bypass. The sub-group of cyanotic patients was compared with non-cyanotic cases and no difference in histamine concentration was found.

\section{Discussion}

Our study demonstrates that plasma histamine concen- tration does not increase consistently during CPB in children. We found a rise in plasma histamine concentration in some patients at each event which was studied. This was only statistically significant at the start of bypass and following removal of the aortic cross-clamp but did not occur in all cases. No on-going release occurred during CPB.

The relationship between haemodynamic variables and histamine concentrations was of particular interest. However, we only demonstrated a significant correlation between histamine and heart rate.

The high baseline values for four cases may have been due to either the pre-medicant or induction drugs. The pre-medicant combination used includes either meperidine or omnopon, both of which opiates have been reported to cause histamine release. However, neither is a major cause of histamine release. Meperidine was administered in combination with promethazine, an $\mathrm{H1}$ antagonist, which would tend to block the effects of histamine release. Cyclopropane has not been shown to cause histamine release and thiopentone is a rare cause of anaphylactic reactions. The extremely high histamine concentration in one child immediately before heparin administration may have been caused by an antibiotic injection.

The increase on initiation of CPB suggests that the prime may be a source of histamine or a trigger of release by contact with the patient's circulating basophils. Previous work has reported plasma histamine of $>80$ $\mathrm{ng} \cdot \mathrm{ml}^{-1}$ in stored blood used in the pump prime. ${ }^{4}$ However, in our series the prime histamine content was not high $\left(<1.5 \mathrm{ng} \cdot \mathrm{ml}^{-1}\right)$. There is no obvious reason for the difference in results of prime histamine assay. In both studies the prime was prepared in the same way and the same assay was used. However, the lower concentrations which we have demonstrated would seem to be more consistent with clinical experience. Although blood pressure usually decreases on initiation of CPB the fall is rarely as catastrophic, nor is it accompanied by bronchospasm or urticaria, as might be expected if the patient were suddenly exposed to the histamine concentrations reported in the previous study. 
The increase in histamine seen on cross-clamp removal in 13 patients may be related to reperfusion of the heart. This would suggest release occurring from cardiac mast cells. There is evidence that histamine release by mast cells is triggered by free radicals which accumulate during ischaemia. ${ }^{15}$ Histamine release at this stage was not demonstrated previously in children ${ }^{3}$ or in adults. ${ }^{2}$

The plasma histamine concentrations were lower than those reported in a previous paediatric study ${ }^{3}$ but similar to those in adults. ${ }^{2}$ In the latter study it was suggested that SNP may have been responsible for some histamine release. However, recent work has shown that SNP is a nitric oxide (NO) generator and that $\mathrm{NO}$ inhibits histamine release from mast cells in isolated guinea-pig hearts. ${ }^{16}$ During our study SNP was used to aid rewarming after cross-clamp removal. If NO does block histamine release this may account in part for the lower concentrations.

The major differences in histamine concentrations between this and the previous paediatric study may be due to different patient groups and bypass techniques. Their subjects $(n=10)$ were drawn from two centres both using deep hypothermic circulatory arrest or low-flow perfusion. These techniques were not used in our subjects and may be predicted to cause more major physiological changes than standard CPB.

Histamine release is relevant to CPB because of its many cardioactive effects. The cardiac effects of histamine are mediated by both $\mathrm{H}_{1}$ and $\mathrm{H}_{2}$ receptors and include positive inotropic and chronotropic actions and production of dysrhythmias. ${ }^{6,8}$ In the isolated guinea-pig heart $\mathrm{H}_{1}$ receptor stimulation has been shown to slow atrioventricular conduction ${ }^{17}$ while in the ventricle the $\mathrm{H}_{2}$ receptor mediates the ventricular chronotropic effect of histamine. ${ }^{18}$ Dysrhythmias are common during and postoperatively in children where much surgery is around the sinus or atrio-ventricular node. Any factors lowering the threshold of the conduction system for dysrhythmia production are of relevance.

The $\mathrm{H}_{1}$ and $\mathrm{H}_{2}$ receptors mediate peripheral vasodilatation which, along with increased vascular permeability, accounts for the cardiovascular collapse associated with anaphylactic shock, and has been implicated in post-CPB capillary leak syndrome. ${ }^{4}$ However, vasoconstrictor effects predominate in the coronary circuit as has been demonstrated by work on human autopsy samples of coronary artery. ${ }^{19}$ This is mediated by $H_{1}$ receptors in smooth muscle cells and is partially masked by $\mathrm{H}_{2}$ receptor mediated vasodilatation, and by relaxing factor liberated through endothelial $\mathrm{H}_{1}$ receptor activation. In the epicardial coronary circulation in $\operatorname{man},{ }^{8}$ and in the pulmonary vasculature in sheep, $\mathrm{H}_{1}$ receptor stimulation causes vasoconstriction. It has recently been demonstrated that $\mathrm{H}_{1}$-mediated pulmonary vasoconstriction increases with increasing age in isolated lamb lungs. ${ }^{9}$ As stated previously, changes in PVR may be critical in this group of patients. We were unfortunately unable to examine the effects of histamine on PVR as pulmonary atrial thermodilution catheters were not placed.

The clinical effects of the relatively low histamine concentrations demonstrated are unclear. The concentrations observed in those patients who released histamine correspond to an "average histamine-release response', as described by Roher, ${ }^{1}$ which in conscious human volunteers elicit the clinical signs of a systemic anaphylactoid reaction. However, we did not demonstrate any relationship between elevated histamine concentrations and hypotension, dysrhythmias or bronchospasm.

In conclusion, histamine is not consistently released during CPB in children. We found small increases in plasma histamine at the start of CPB and when the aortic cross-clamp was released in some children but were unable to isolate any factors rendering these subjects more prone to histamine release. We have not documented an association between plasma histamine concentrations and intraoperative haemodynamic problems.

\section{References}

1 Roher HD, Lorenz W, Lennartz H, et al. Plasma histamine levels in the course of several standard operations: influence of anaesthesia, surgical trauma and blood transfusion. Klinische Wochenschrift 1982; 60: 926-34.

2 Man WK, Steger AC, Hosking SW, Taylor KM. Histamine release during cardiopulmonary bypass. Perfusion 1990; 5: 31-40.

3 Marath A, Man W, Taylor KM, et al. Plasma histamine profiles in paediatric cardiopulmonary byass. Agents Actions 1988; 23: 339-42.

4 Marath A, Man WK, Taylor KM. Histamine release in paediatric cardiopulmonary bypass - a possible role in the capillary leak syndrome. Agents Actions 1987; 20: 299-302.

5 Giles $R W$, Heise G, Wilcken DE. Histamine receptors in the coronary circulation of the dog. Circ Res 1977; 40: 541-6.

6 Borchard U, Hafner D, Hirth C. Electrophysiological actions of histamine and H1- and H2-receptor antagonists in cardiac tissue. Agents Actions 1986; 18: 186-90.

7 Levi $R$, Chenouda AA, Trzeciakowski JP, et al. Dysrhythmias caused by histamine release in guinea pigs and human hearts. Klinische Wochenschrift 1982; 60: 965-71.

8 Bristow MR, Ginsburg R, Harrison DC. Histamine and the human heart: the other receptor system. Am J Cardiol 1982; 49: 249-51.

9 Gordon JB, de Clety SC, Chu K. Developmental changes 
in effects of histamine on segmental pulmonary vascular resistances. J Appl Physiol 1991; 71: 150-8.

10 Maehara T, Novak I, Wyse RK, Elliot MJ. Perioperative monitoring of total body water by bio-electrical impedance in children undergoing open heart surgery. Eur J Cardiothorac Surg 1991; 5: 258-65.

11 Withington DE, Elliot $M$, Man WK. Histamine release during paediatric cardiopulmonary bypass. Agents Actions 1991; 33: 200-3.

12 Hatch DJ, Sumner E (Eds). Appendix 1. In: Textbook of Paediatric Anaesthetic Practice. London: Balliere Tindall, 1989: 580-1.

13 Hatch DJ, Sumner $E(E d s)$. Anaesthesia for patients with cardiac disease. In: Textbook of Paediatric Anaesthetic Practice. London: Balliere Tindall, 1989; 319.

14 Man WK, Saunders JH, Ingoldby C, Spencer A. The effect of pentagastrin on histamine output on the stomach in patients with duodenal ulcer. Gut 1981; 22: 916-22.

15 Masini E, Bianchi S, Gambassi F, et al. Ischaemia reperfusion injury and histamine release in isolated perfused guinea-pig heart: Pharmacological interventions. Agents Actions 1990; 30: 198-201.

16 Masini E, Bianchi S, Mugnai L, et al. The effect of nitric oxide generators on ischaemia reperfusion injury and histamine release in isolated perfused guinea-pig heart. Agents Actions 1991; 33: 53-6.

17 Levi R, Ganellin CR, Allan G, Willens HJ. Selective impairment of atrioventricular conduction by 2-(2-pyridyl)ethylamine and 2-(2-thiazolyl)-ethylamine, two histamine $\mathrm{H}_{1}$-receptor agonists. Eur J Pharmacol 1975b; 34: 237-40.

18 Levi $R$, Zavecz $J H$. Acceleration of idioventricular rhythms by histamine in guinea pig heart. Mediation by $\mathrm{H}_{2}$ receptors. Circ Res 1979; 44: 847-55.

19 Toda $N$. Is histamine a human coronary artery vasospastic substance? Trends Pharmacol Sci 1987; 8: 289-90. 